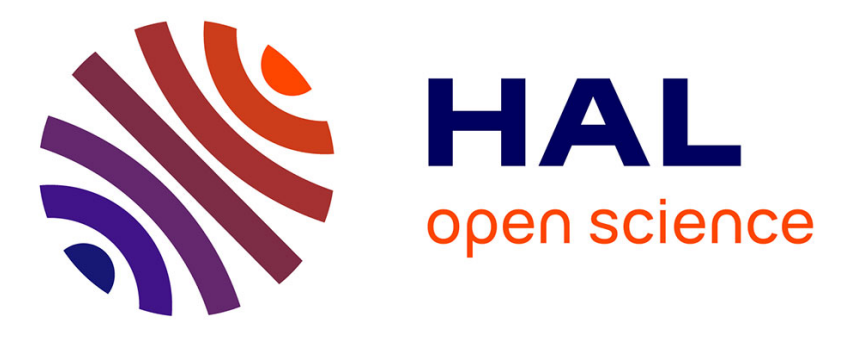

\title{
Influence of relative humidity and temperature on the sol-gel transition of a siloxane surface treatment
}

Quentin Hatte, Pierre-Antoine Dubos, Nadia Guitter, Mireille Richard-Plouet, Pascal Casari

\section{- To cite this version:}

Quentin Hatte, Pierre-Antoine Dubos, Nadia Guitter, Mireille Richard-Plouet, Pascal Casari. Influence of relative humidity and temperature on the sol-gel transition of a siloxane surface treatment. Journal of Sol-Gel Science and Technology, 2019, 90 (2), pp.230-240. 10.1007/s10971-019-04929-0 . hal-02132844

\section{HAL Id: hal-02132844 \\ https://hal.science/hal-02132844}

Submitted on 21 Oct 2019

HAL is a multi-disciplinary open access archive for the deposit and dissemination of scientific research documents, whether they are published or not. The documents may come from teaching and research institutions in France or abroad, or from public or private research centers.
L'archive ouverte pluridisciplinaire HAL, est destinée au dépôt et à la diffusion de documents scientifiques de niveau recherche, publiés ou non, émanant des établissements d'enseignement et de recherche français ou étrangers, des laboratoires publics ou privés. 


\title{
Influence of relative humidity and temperature on the sol-gel transition of a siloxane surface treatment
}

\author{
Quentin Hatte $\mathbb{C}^{1,2,3} \cdot$ Pierre-Antoine Dubos $^{2} \cdot$ Nadia Guitter $^{4} \cdot$ Mireille Richard-Plouet $^{3} \cdot$ Pascal Casari $^{2}$
}

\begin{abstract}
This work investigates the effect of relative humidity $(\mathrm{RH})$ and temperature on drying phenomenon of a siloxane coating during the sol-gel process. An experimental approach was taken, due to a lack of available data in existing literature. Dynamic Vapor Sorption, Fourier Transform Infra-Red spectroscopy and X-ray Photoelectron Spectroscopy analyses were performed during sol drying, while controlling RH and temperature. The drying time increased exponentially when RH was increased. This was linked to water uptake and evaporation rate decrease, forming a more condensed coating. The thermally activated process was fitted by the Arrhenius law with an activation energy of $41.7 \mathrm{~kJ} \mathrm{~mol}^{-1}$. A double exponential law was proposed to describe the time needed for drying the sol as a function of temperature and RH. Finally, differences in the gel formed were clearly demonstrated. Between a RH of 30 and 50\%, the gel formation turned from a dry-before-gel to a gelbefore-dry phenomenon, stressing the importance of temperature and RH control during the drying process of the sol.
\end{abstract}

\section{Graphical Abstract}

Temperature and relative humidity have an exponential influence on drying time. The sol-gel kinetics is also modified, which leads to a chemical evolution of the formed gel. This change is related to the relationship between drying and chemical reaction rates.

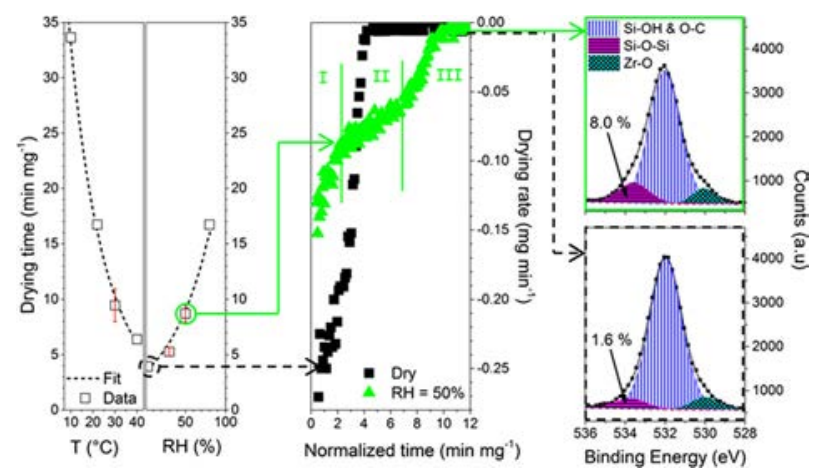

Quentin Hatte

quentin.hatte@univ-nantes.fr

$\triangle$ Pierre-Antoine Dubos

pierre-antoine.dubos@univ-nantes.fr

1 Institut de Recherche Technologique Jules Verne, Chemin du Chaffault, 44340 Bouguenais, France
2 Institut de recherche en génie civil et mécanique, GeM Université de Nantes, UMR6183, IUT de Saint-Nazaire, 58 rue Michel Ange, BP 420, 44606 Saint-Nazaire, Cedex, France

3 Institut des Matériaux Jean Rouxel, (IMN) Université de Nantes, CNRS, 2 rue de la Houssinière - BP 32229, 44322 Nantes, Cedex, France

4 Socomore, ZI du Prat - CS 23707, 56037 Vannes, Cedex, France 


\section{Highlights}

- Sol drying on steel was monitored by DVS and FTIR diffuse reflection.

- XPS analyses on films revealed differences with temperature and RH conditions.

- The drying time increased exponentially when RH was increased, due to water uptake.

- The process was fitted by the Arrhenius law with activation energy of $41.7 \mathrm{~kJ} \mathrm{~mol}^{-1}$.

- A general law was proposed to describe sol drying time according to temperature \& RH.

Keywords Drying $\cdot$ Temperature $\cdot$ Relative humidity $\cdot$ Sol-gel transition $\cdot$ Fourier transform infra-red spectroscopy $\cdot \mathrm{X}$-ray photoelectron spectroscopy

\section{Introduction}

The first sol-gel process experiment was published by Joseph Ebelmen in 1845 [1]. Since then, the technology has developed to the point that the process is now used to form a multitude of materials. Among these, coatings or thin layers have been developed in various applications ranging from electronics (e.g., photovoltaic) [2], to optics (e.g., antifogging, self-cleaning) [3], or protection (e.g., anti-corrosion) [4]. The process has proven to be versatile and allows the application of oxide or organic-inorganic hybrid coatings at low temperature with practically all types of chemical and physical properties. Moreover, the use of liquid solutions allows it to be applied on many substrates of various shapes.

The literature demonstrates an awareness of mechanisms which drive the transition from the liquid- to the gel state. The various hydrolysis-condensation reactions are accompanied by the evaporation of the solvent(s). This step becomes dominating when the sol is applied. Among the different deposition techniques, spin- and dip-coating [5-8] are the most studied ones. Despite their differences, the basic mechanisms of condensation and evaporation of the wet film remain the same. Before deposition, a 'solution aging' process takes place, where precursors, reactive agents and solvents are mixed for a controlled time. This may be necessary, depending on the chemical conditions, in order to get a more stable product [9] or a coating with desired properties [10,11].

The sol is then deposited. The large exchange surface created with the atmosphere induces a rapid equilibrium of the volatile species between the layer and the atmosphere. Therefore, at this time, evaporation is the main cause of the evolution of the composition of the film, though it can trigger or be accompanied by other effects such as water absorption or viscous flow [7]. Evaporation is also accompanied by the solidification of the film by subunits crosslinking favored by spatial gathering. The system has evolved over time in both composition and spatial distribution, which can make modeling complicated. Nevertheless, starting from hypotheses, several authors were able to obtain models to clarify the mechanisms during drying process [12-15].

Cairncross and his co-workers [12] performed a simulation of the tetramethylorthosilicate drying-reaction process in aqueous alcoholic solution and acidic catalysis. Convection, diffusion and chemical reactions were all taken into account to establish their model. Galerkin's finite element methods were used to solve corresponding equations. Theoretical gelation point was calculated using literature [5] to set the necessary conversion rate. This showed a gel point before, during or after the evaporation of the solvents, potentially involving a change in the microstructure of the gel. E.G. if evaporation is not limited by external conditions, concentration of reagents and products varies, depending on the thickness. Alcohol and water - initially present in solution - are also products of condensation reactions. Reactions on the sol surface are accelerated due to their heightened volatility. This could lead to 'skinning' the sol surface can solidify, before the interior, thus forming a skin - if the coating is thick enough. It was also numerically proven, that modification of the ambient drying conditions or kinetic reaction alters the drying process. These parameters were then used to plot drying regime maps.

As previously stated, the sol drying process is complex. It is a result of chemical condensation reactions and evaporation of solvents. The substantial variety of coatings causes a multitude of drying processes. In addition, several phenomena may occur for each coating, depending on the ambient conditions of deposition [12, 16-19]. Several numerical studies show that a change in ambient conditions could lead to an alteration in the drying regime and thus a modification of the gel formed. The goal of this paper is to provide new experimental data dealing with the influence of the ambient condition on the sol-gel transition. The influence of ambient temperature and Relative Humidity (RH) on sol-gel transition was investigated with the use of in situ Fourier Transform Infra-Red spectroscopy (FTIR) and Xray Photoelectron Spectroscopy (XPS) analysis. Gravimetric analyses were also performed with a Dynamic Vapor Sorption device (DVS), usually used for determining moisture diffusion in materials. 


\section{Material and methods}

\subsection{Samples Preparation}

The sol is an organic-inorganic hybrid surface treatment used before painting. This adhesion promoter creates covalent bonds by condensation reaction between hydroxyl groups present on the surface of the metal substrate and from hydrolyzed precursors. The organic part of the coating reacts with the paint primer to form chemical bonds, such as epoxy-amine bonds for epoxy paints. This technology has been described in several articles [20-23]. The sol is composed of Glycidyl 3- (trimethoxysilyl) propyl ether (GLYMO), zirconium(IV) tetra-1-propoxide (ZrTPO) and other precursor(s). These components, stirred in hydroalcoholic solution for an hour, create the sol. Then, this solution was sprayed to the surface of $30 \mu \mathrm{m}$ thick carbon steel sheets, which had been cut into discs (diameter of 8 $\mathrm{mm})$. Before sol application, the samples were cleaned with a dilute phosphoric acid solution, rinsed with warm water $\left(60^{\circ} \mathrm{C}\right)$ then dried with compressed air. The sol mass deposited was about $3 \mathrm{mg}$. After the application, the evolution of the mass was measured by DVS. The sol-gel transformation was also characterized by FTIR spectroscopy. Finally, the chemical composition of the gel formed was identified by XPS.

\subsection{Dynamic vapor sorption gravimetric analysis}

The drying kinetics were monitored using an IGAsorp DVS analyser, which measures a mass sample, whilst controlling temperature and relative humidity.

See Table 1 for Measurement conditions and accuracy.

The study looks at two parameters: $\left(t_{\mathrm{sat}}\right)$ - the time to reach a saturation plateau and $M_{\text {sat }}$-the value of the saturation plateau due to solvent evaporation mass loss. To overcome the differences in initial thickness related to the deposition process, time was normalized by the sol mass initially deposited (typically $3 \mathrm{mg}$ ). The mass was divided by the initial mass of each sample in order to plot a mass variation that can be compared between experiments. To evaluate repeatability, some conditions were replicated at least three times. These results are presented including type A standard uncertainty.

Table 1 Measurement condition summary for the DVS test

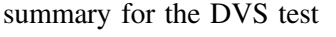

\subsection{Infra-red Spectroscopy Analysis}

\subsubsection{Experiments}

FTIR spectra were recorded in the 6000 to $600 \mathrm{~cm}^{-1}$ region, using a Bruker Vertex 70 spectrometer and a Praying Mantis diffuse reflection setup. Temperature was set to $22{ }^{\circ} \mathrm{C}$. Samples were set in a diffuse reflection environmental chamber with $\mathrm{KBr}$ or $\mathrm{CaF}_{2}$ windows (see diagram in Fig. 1) in order to control relative humidity. The RH was adjusted in the environmental chamber using dissolved salts. Thus, inside a closed space they produce a desired equilibrium vapor pressure, as detailed in previous works [24, 25]. Three salts were selected: $\mathrm{CaCl}_{2}, \mathrm{Ca}\left(\mathrm{NO}_{3}\right)_{2}$ and $\mathrm{NaCl}$ to fix $\mathrm{RH}$ to 30,50 and $75 \%$ at $22{ }^{\circ} \mathrm{C}$, respectively, according to [24, 26, 27]. A final experiment used silica gel to obtain a dry atmosphere $(\mathrm{RH}<5 \%)$.Infra-red spectrum was recorded every minute for $1 \mathrm{~h}$ with a spectral resolution of $2 \mathrm{~cm}^{-1}$. A reference was analyzed in each atmosphere prior to experiments. The pseudo-absorbance was recorded as $\log \left(R_{\text {sample }} / R_{\text {ref }}\right)$, where $R_{\text {sample }}$ and $R_{\text {ref }}$ are the diffuse reflectance of the sample and the reflectance reference respectively.

\subsubsection{Spectral Treatments}

In the literature, several spectral treatment methods were reported [28, 29]. Evolution of the characteristic peak intensity has been plotted, as shown elsewhere [30]. Integrated intensity change in the infra-red band at $3500 \mathrm{~cm}^{-1}$ was investigated as a function of time after sol deposition. This wide band (2700-3700 $\mathrm{cm}^{-1}$ region) is due to the $\mathrm{O}-\mathrm{H}$ stretching modes attributed to alcohol, water and silanol

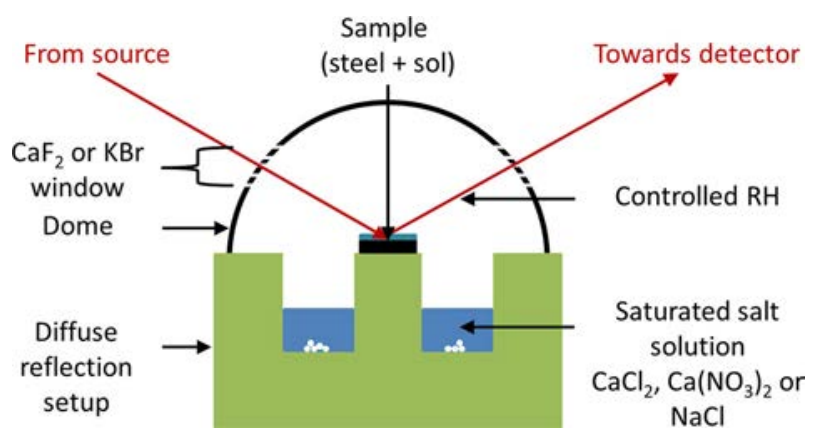

Fig. 1 Cross sectional scheme of the diffuse reflection environmental chamber

\begin{tabular}{|c|c|c|c|c|c|}
\hline \multicolumn{3}{|c|}{ Accuracy } & \multicolumn{3}{|c|}{ Measurement conditions } \\
\hline $\mathrm{T}$ & RH & Mass & $\begin{array}{l}\text { Time between } \\
\text { measurements }\end{array}$ & $\mathrm{T}$ range $(\mathrm{RH}=80 \%)$ & $\mathrm{RH}$ range $\left(T=22^{\circ} \mathrm{C}\right)$ \\
\hline $\begin{array}{l}+/-1^{\circ} \\
\mathrm{C}\end{array}$ & $+I-1 \%$ & $+/-0.2 \mathrm{ng}$ & $1 \mathrm{~s}$ & $10-40^{\circ} \mathrm{C}$ & $<5-80 \%$ \\
\hline
\end{tabular}


groups from hydrolyzed precursor [31, 32]. It overlaps the $\mathrm{C}-\mathrm{H}$ stretching region $\left(2700-2900 \mathrm{~cm}^{-1}\right)$. Due to these multiple attributions, the evolution of the intensity of this band was chosen as a macro indicator of the degree of progress of the sol to gel transition, which gathers the state of advancement of hydrolysis, condensation and solvent evaporation. For each spectrum the infra-red band was integrated between 2700 and $3700 \mathrm{~cm}^{-1}$. Since there was no constant peak common to all the samples, this integrated intensity was divided by the total integrated intensity of the spectrum in order to facilitate sample comparisons. The evolution of the normalized integrated intensities was plotted versus time after the deposition at laboratory temperature $\left(22^{\circ} \mathrm{C}\right)$ and for four different $\mathrm{RH}$.

The same procedure was applied with a band at $1100 \mathrm{~cm}$ ${ }^{-1}$. According to the literature [33-36], this band can be attributed to the asymmetric stretching vibrations of the $\mathrm{Si}-$ $\mathrm{O}-\mathrm{Si}$ bonds. In this case, the ratio was normalized by the final value for each condition and then plotted versus time in order to give an insight on kinetics. At the end of the process, the value of this band is constant, therefore indicating the end of the condensation stage. The evolution of the ratio permits tracking of the proportion of $\mathrm{Si}-\mathrm{O}-\mathrm{Si}$ bonds created during sol-gel process.

\subsection{X-Ray photoelectron spectroscopy analysis}

XPS measurements were performed on a Kratos Axis Ultra and Axis Nova spectrophotometers (see Table 2).

Two samples, dried in different conditions, were compared: a dry atmosphere with silica-gel $(\mathrm{RH}<5 \%)$ and an atmosphere with a RH of $50 \%$, at $22{ }^{\circ} \mathrm{C}$ in both cases. All high-resolution spectra were analyzed using CasaXPS software (Neal Fairley. Copyright@ 2005 Casa Software Ltd; 2005). The background was accounted for using a U2 Tougaard curve and Gaussian-Lorenzian peaks were chosen to fit the different components.

\section{Results and Discussion}

\subsection{Influence of Relative Humidity on the Sol to Gel Transition}

Figure 2 plots the mass variation during the sol drying according to the relative humidity for a temperature of $22^{\circ} \mathrm{C}$. The mass variation initially decreases before stabilizing at a constant value. It can be observed that drying time was influenced greatly by $\mathrm{RH}$. The former altered as $\mathrm{RH}$ increased. This could be due to a decrease of the evaporation rate. Indeed, as explained by Liu et al. [37], the drying rate of water/alcohol mixture decreases with RH. Since the vapor pressure of alcohol is higher than that of
Table 2 Summary of the experimental parameters used for XPS analysis

\begin{tabular}{|c|c|c|}
\hline \multicolumn{2}{|l|}{ Source } & $\begin{array}{l}\text { Monochromatic Al K } \alpha \text { source } \\
1486.6 \mathrm{eV}(150 \mathrm{~W})\end{array}$ \\
\hline \multicolumn{2}{|l|}{ Charge neutralizer } & ON \\
\hline \multicolumn{2}{|l|}{ Area analyzed } & $700 \times 300 \mu \mathrm{m}^{2}$ \\
\hline \multirow[t]{2}{*}{ Wide scan } & $\begin{array}{l}\text { Binding energy } \\
\text { range: }\end{array}$ & $0-1200 \mathrm{eV}$ \\
\hline & Pass energy & $160 \mathrm{eV}$ \\
\hline \multirow{3}{*}{$\begin{array}{l}\text { High-resolution } \\
\text { spectra }\end{array}$} & Pass energy & $40 \mathrm{eV}$ \\
\hline & Resolution & $0.1 \mathrm{eV}$ \\
\hline & $\begin{array}{l}\text { Core level } \\
\text { recorded }\end{array}$ & $\begin{array}{l}\text { Si } 2 p, \mathrm{O} 1 s, \mathrm{~N} 1 s, \mathrm{C} 1 s \text { and } \mathrm{S} \\
2 p\end{array}$ \\
\hline \multicolumn{2}{|l|}{ Calibration } & $\mathrm{C} 1 \mathrm{~s}(\mathrm{C}-\mathrm{C})$ to $285 \mathrm{eV}$ \\
\hline \multicolumn{2}{|c|}{$\begin{array}{l}\text { Minimal number of measurements } \\
\text { per test }\end{array}$} & 4 \\
\hline \multirow{2}{*}{$\begin{array}{l}\text { RH level during } \\
\text { drying }\end{array}$} & Test 1 & $<5 \%$ \\
\hline & Test 2 & $50 \%$ \\
\hline
\end{tabular}

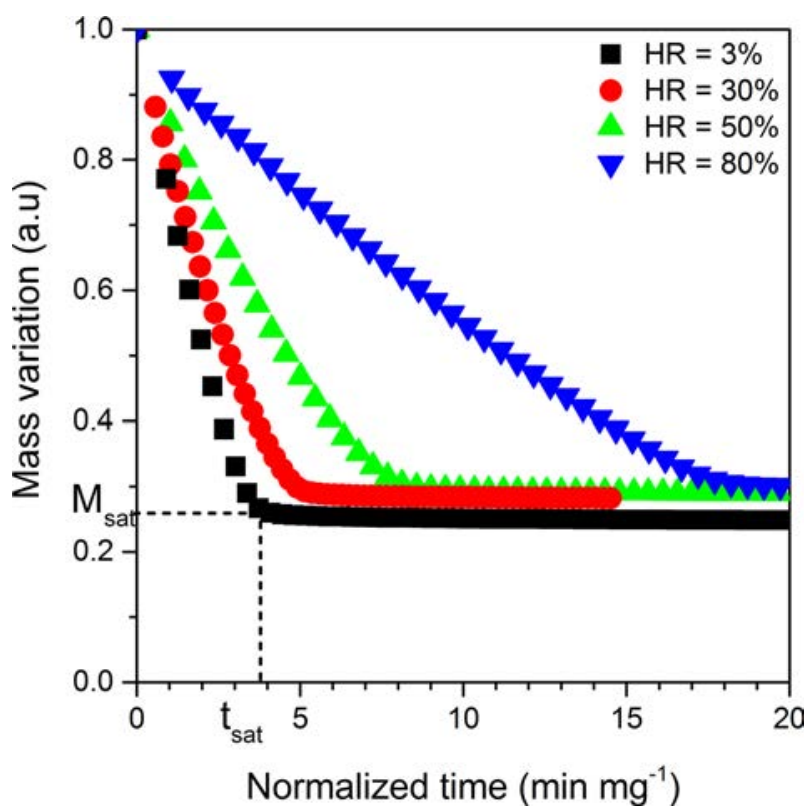

Fig. 2 Definition of $\mathrm{M}_{\mathrm{sat}}$ and $\mathrm{t}_{\mathrm{sat}}$ and influence of relative humidity at $22{ }^{\circ} \mathrm{C}$ on the mass variation during sol-gel process, black squares: $3 \%$ RH, red circles: $30 \% \mathrm{RH}$, green triangles: $50 \% \mathrm{RH}$, reverse blue triangles: $80 \% \mathrm{RH}$

water it evaporates first. Then, in a second step, water evaporation takes place and it is slower when RH increases. Actually, evaporation process is a function of the difference between the relative vapor pressure inside the chamber $\left(P_{a}\right)$ and at the solution surface $\left(P_{s}\right)$. For each species, the number of molecules particles $J$, evaporating per unit of time from the unit area can be described by the Knudsen equation (Eq. 1) as discussed in other studies [38, 39], where $P_{l i q}$ is the pressure of the liquid during evaporation, 
$P_{\text {eq }}$ is the equilibrium pressure of the vapor/liquid coexistence at $T_{\text {liq }}-$ the temperature of the liquid, $m$ is the mass of a molecule and $k_{\mathrm{B}}$ the Bolzmann constant.

$J=\frac{\left(P_{\mathrm{liq}}-P_{\mathrm{eq}}\right)}{\sqrt{2 \pi m k_{\mathrm{B}} T_{\mathrm{liq}}}}$.

In a system where the liquid-vapor interface is flat, the equilibrium pressure is the vapor pressure. So when RH increases, the flux of evaporating water molecules decreases. Moreover, it was shown [37, 40] that the evaporation of ethanol or water/ethanol mixture can be accompanied by water vapor condensation at the beginning of the evaporation. In conclusion, the quantity of condensed water increases with atmosphere moisture content which, leads to a slowing down of the whole drying process.

Experimentally, the relationship between the saturation mass and RH is linear (Fig. 3a) whereas it is exponential with the time needed to dry (Fig. 3b). The equilibrium saturation mass was greater when $\mathrm{RH}$ increased. The film was prepared from a hydro-alcoholic solution, causing the organic solvent to be eliminated faster, as cited earlier. The aqueous proportion in the wet film increased to reach a final equilibrium state fixed by the relative humidity.

The chemistry of the final gel formation is also influenced by RH. Figure 4a, b show the O 1 s XPS spectra of two hybrid organic-inorganic gels formed under dry conditions (Fig. 4a) and under an atmosphere with $\mathrm{RH}$ of $50 \%$

(a)

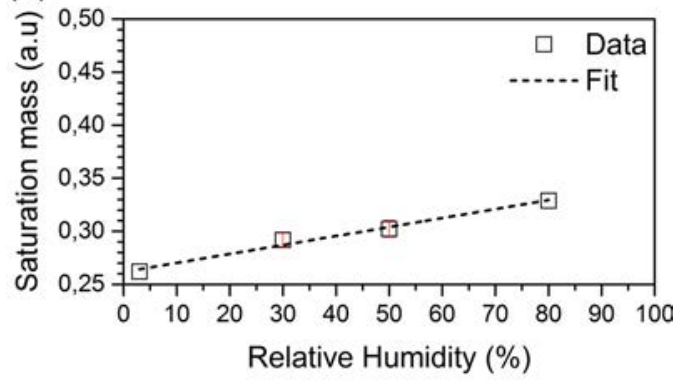

(b)

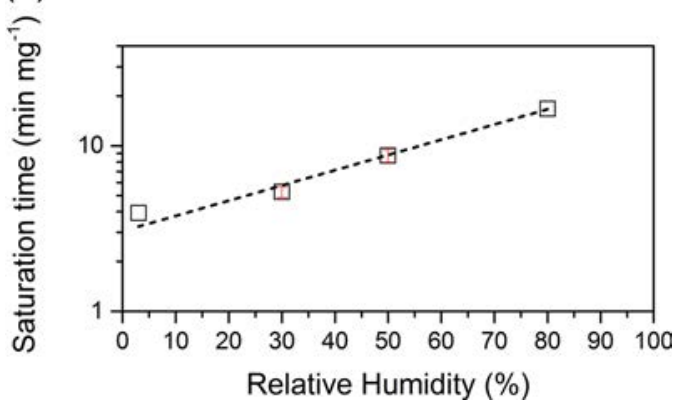

Fig. 3 Influence of relative humidity during sol-gel process at $22{ }^{\circ} \mathrm{C}$ on a saturation mass (black dotted line: linear fit to guide eye) and $\mathbf{b}$ saturation time (black dotted line: exponential fit to guide the eye)
(Fig. 4b). The peak was decomposed as three contributions: one at a binding energy of $531.3 \mathrm{eV}$ was attributed to oxygen of the $\mathrm{Zr}$ oxide network according to the literature [41, 42] and confirmed by $\mathrm{Zr} 3 \mathrm{~d}$ spectra analysis (not shown here), and a further two, at 532 and $533 \mathrm{eV}$. The former is typical for the hydroxyl groups or water molecule on the surface of the sample or silanol bonds $(\mathrm{Si}-\mathrm{OH})$ and $\mathrm{O}-\mathrm{C}$ in the gel. The peak at higher binding energy is reported in the literature to correspond to the silicon oxide skeleton [43]. The proportion of $\mathrm{O}-\mathrm{Si}$ contribution was modified by the presence of moisture in the atmosphere during the drying stage, evolving from 1.6 to $8 \%$ when the atmosphere is dry or when $\mathrm{RH}=50 \%$, respectively. This indicates that the hydroxyl groups were consumed in the condensation reaction of the precursors leading to an increase in the $\mathrm{Si}-\mathrm{O}$ skeleton formation. These observations suggest that after drying in the humid atmosphere, the film was more condensed. This observation is consistent with the $\mathrm{O} / \mathrm{Si}$ ratio analysis. Indeed this ratio was equal to 0.06 in the dry atmosphere versus 0.09 for an atmosphere with a $\mathrm{RH}$ of $50 \%$. This could be due to differences between solvent evaporation rates. In the dry atmosphere, evaporation rates were faster, hindering condensation for which more time would have been necessary.

This assumption is consistent with FTIR spectra analyses. Figure 5 a shows the evolution of the normalized $\mathrm{Si}-$
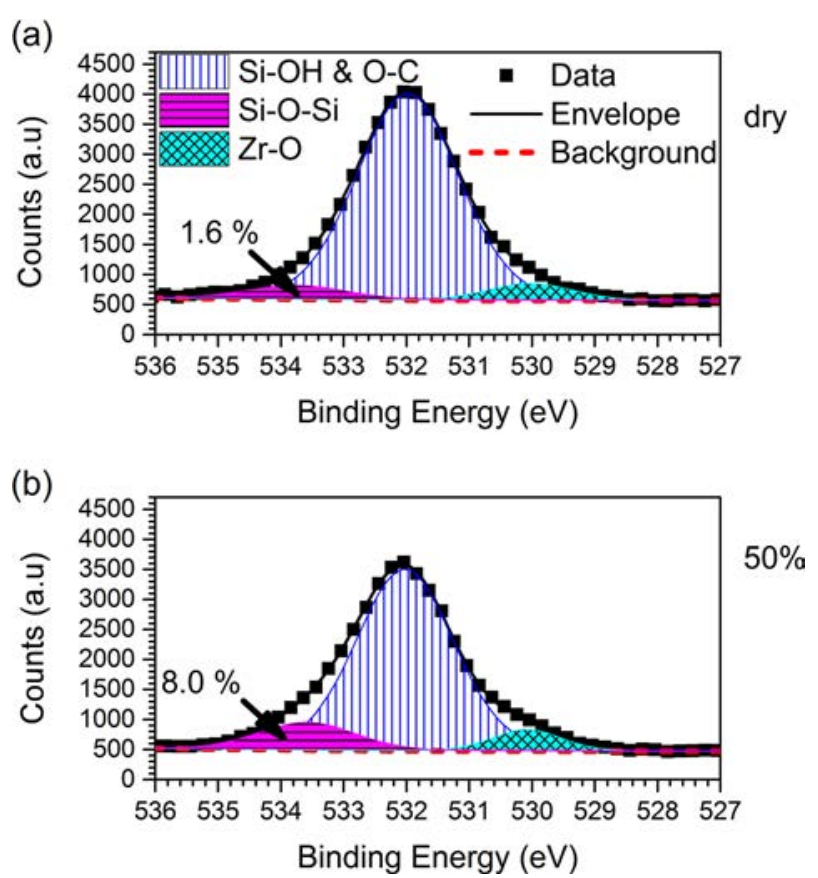

Fig. $4 \mathrm{O} 1 \mathrm{~s}$ spectra of a film dried at $22^{\circ} \mathrm{C}$ in a a dry atmosphere and b in an atmosphere with a $\mathrm{RH}$ of $50 \%$, black squares: experimental data, red dotted line: background, area with vertical blue lines: $\mathrm{H}_{2} \mathrm{O}$, $\mathrm{Si}-\mathrm{OH}$ and $\mathrm{O}-\mathrm{C}$ contributions, pink with horizontal lines area: $\mathrm{Si}-\mathrm{O}$ contribution, green hatched area: $\mathrm{Zr}-\mathrm{O}$ contribution, black line: sum of contribution 
(a)

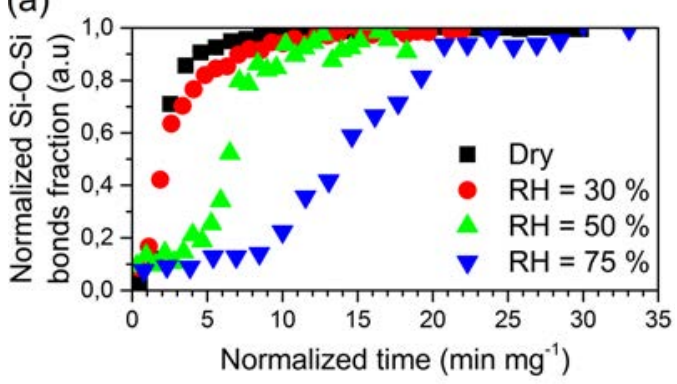

(b)

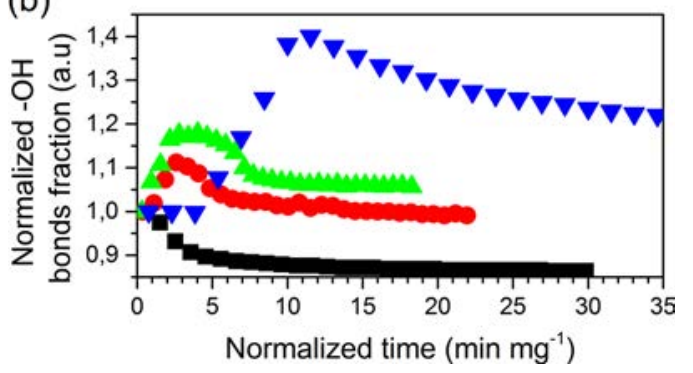

Fig. 5 Evolution of normalized bonds fraction during sol-gel process at $22^{\circ} \mathrm{C}$ a $\mathrm{Si}-\mathrm{O}-\mathrm{Si}$ bonds fraction $\mathbf{b}-\mathrm{OH}$ bonds fraction. Black squares: dry, red circles: $30 \% \mathrm{RH}$, green triangles: $50 \% \mathrm{RH}$, reverse blue triangles: $75 \% \mathrm{RH}$

O-Si bonds fraction after sol deposition. In a dry atmosphere, the formation of the $\mathrm{Si}-\mathrm{O}-\mathrm{Si}$ network was very fast compared to other conditions. After $3 \mathrm{~min} \mathrm{mg}^{-1}$ there was no longer visible evolution. Moreover, the $-\mathrm{OH}$ bonds fraction dropped and stabilized quickly, (see Fig. 5b). For a RH of 30 and $50 \%$, evolutions of the curves are similar. Initially, normalized -OH bonds fraction increased, doubtless because of water uptake as explained before. Secondly, the fraction stabilized according to the evaporation rate fixed by the RH value. Finally, it decreased depending on the atmosphere moisture content. An increase in RH leads to a greater time to reach the equilibrium. These results are in accordance with DVS experiments and Fig. 3a, b. Water uptake increased with atmosphere moisture content which, in turn, slowed the evaporation process and increased the time left for condensation reactions (as shown in Fig. 5a).

\subsection{Influence of Temperature on Sol to Gel Transition}

Figure 6 shows the mass variation of samples in an atmosphere with an RH of $80 \%$ at various drying temperatures.

With regard to the evolution of the plateau of saturation, no difference was noticed between $22^{\circ} \mathrm{C}, 30^{\circ} \mathrm{C}$ and $40{ }^{\circ} \mathrm{C}$ (Fig. 7a) whereas, the saturation mass was greater at $10^{\circ} \mathrm{C}$. The process may have been too slow to permit solvent evaporation before the gelation of precursors and thus enabling solvent encapsulation. This idea of gelation-

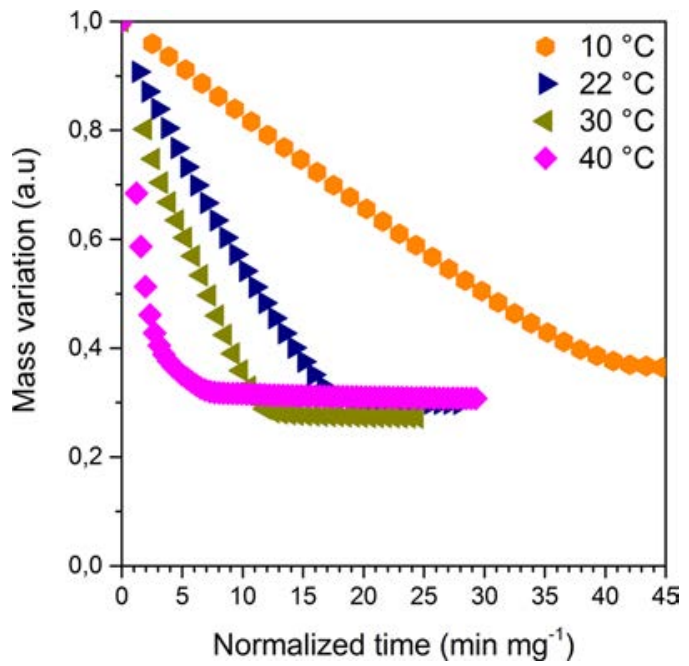

Fig. 6 Influence of temperature on the mass variation during sol-gel process in an atmosphere with $\mathrm{RH}$ of $80 \%$, pink rhombuses: $40^{\circ} \mathrm{C}$, brown left oriented triangles: $30^{\circ} \mathrm{C}$, blue right oriented triangles: $22{ }^{\circ} \mathrm{C}$, orange hexagons: $10^{\circ} \mathrm{C}$

before-drying is developed in the discussion focussing on the RH influence.

However, the experimental data does clearly indicate a strong influence of temperature on the kinetics of drying. This is to be expected since, according to the literature [4446], evaporation and all the sol-gel process comply with the Arrhenius law (Eq. (2)).

$k=A e^{-E_{a} / R T}$,

Where $k$ is the constant rate of reaction $\left(\mathrm{s}^{-1}\right), A$ is the preexponential term $\left(\mathrm{s}^{-1}\right), E_{\mathrm{a}}$ is the energy of activation $(\mathrm{kJ}$ $\left.\mathrm{mol}^{-1}\right), R$ is the universal gas constant $\left(8.314 \mathrm{~J} \mathrm{~mol}^{-1}\right)$ and $T$ is the temperature $(\mathrm{K})$. This exponential influence is visible in Fig. $7 b$.

For each condition, the natural logarithm of the mass variation was plotted versus normalized time, a linear dependence was found between these parameters.

Obtaining a straight line indicates the sol-gel drying (sum of a multitude of reactions) follows a pseudo-first-order chemical kinetics. The constant rate reaction $k$ was calculated for each temperature and then plotted versus the inverse of the temperature in order to calculate the activation energy $E_{a}$. The value obtained from the slope is $65.3 \mathrm{~kJ}$ mol $^{-1}$ (Fig. 8a).

A modified equation (Eq. (3)) can be used to take into account the time needed to reach the saturation mass corresponding to the end of the drying process $t_{s}$ (s) (instead of the constant rate reaction).

$\ln t_{s}=-\ln A_{s}+\left(\frac{E_{a}}{R T}\right)$. 
In this way, the activation calculated is $41.7 \mathrm{~kJ} \mathrm{~mol}^{-1}$ (Fig. 8b). Both activation energies calculated are in accordance with previous works which reports a gelation activation energy between 40 and $70 \mathrm{~kJ} \mathrm{~mol}^{-1}$ for $\mathrm{HCl}-$ catalyzed tetraethyl orthosilicate system depending on, for

(a)

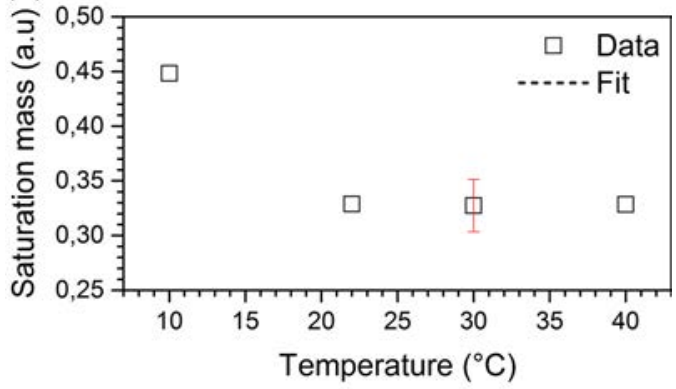

(b)

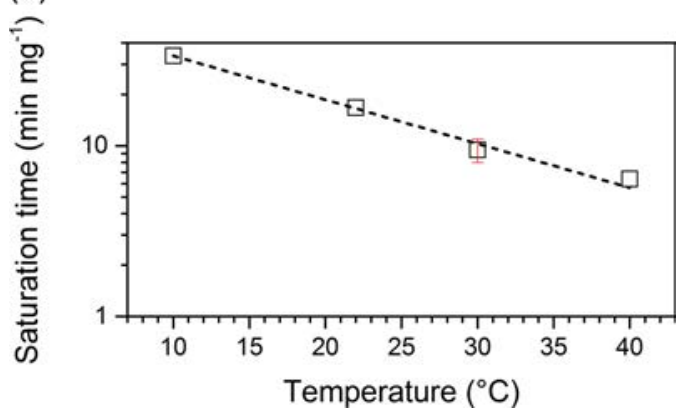

Fig. 7 Influence of temperature during sol-gel process in an atmosphere with $\mathrm{RH}$ of $80 \%$ on a saturation time and $\mathbf{b}$ saturation mass (black dotted line: exponential fit to guide the eye)

(a)
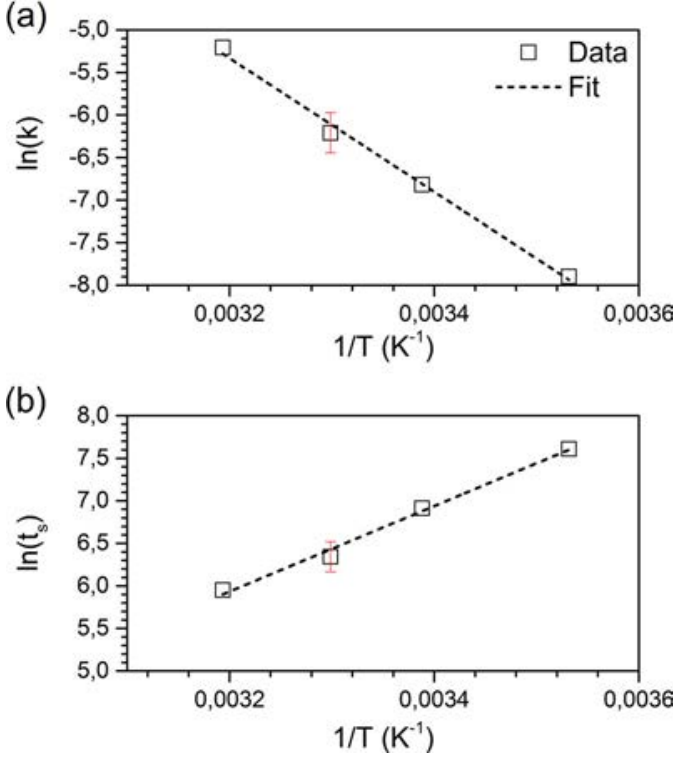

Fig. 8 Method for determining the activation energy $E_{a}$ : a from constant rate reaction $\mathrm{k}$ and $\mathbf{b}$ from saturation time, squares: experimental data, dotted line: linear fit example, water concentration $[47,48]$. The difference between both values may be due to a difference between the reactions we are probing when considering saturation mass and saturation time. The constant rate $k$ could be related to the chemical reaction rate in solution at the beginning of drying whereas the saturation time would be more related to the whole process. Since the time scale is different, the activation energies found are also different.

An empirical law, inspired by Arrhenius, was used in order to link the saturation time to both temperature and $\mathrm{RH}$ (Eq. (4)). The activation energy calculated from saturation time was chosen to get an insight into the whole process.

$t_{s}=\exp (B \times \mathrm{RH}) \times C \cdot \exp \left(\frac{E_{a}}{R \times T}\right)$.

We could estimate the different fitted parameters:

$B=$ constant $=0.0196$

$C=$ constant comprising the pre-exponential factor of the Arrhenius law $=5 \cdot 24 \cdot 10^{-6} \mathrm{~s}^{-1}$

$E_{a}=$ activation energy $=41.7 \mathrm{~kJ} \mathrm{~mol}^{-1}$

$\mathrm{RH}=$ relative humidity $(\%)$

The agreement with the experimental data is very good (Fig. 9). By using this law, it is now possible to obtain the time to reach saturation, for any temperature and $\mathrm{RH}$ condition, within the studied range. The time needed for drying ranges between $4 \mathrm{~min} \mathrm{mg}^{-1}$ for a temperature of $22^{\circ} \mathrm{C}$ and a relative humidity $<5 \%$ and $34 \mathrm{~min} \mathrm{mg}^{-1}$ for a temperature of $10{ }^{\circ} \mathrm{C}$ and a relative humidity of $80 \%$. It corresponds, approximately, to a total time between 12 and $100 \mathrm{~min}$ when the mass deposited is around to $3 \mathrm{mg}$. (a)

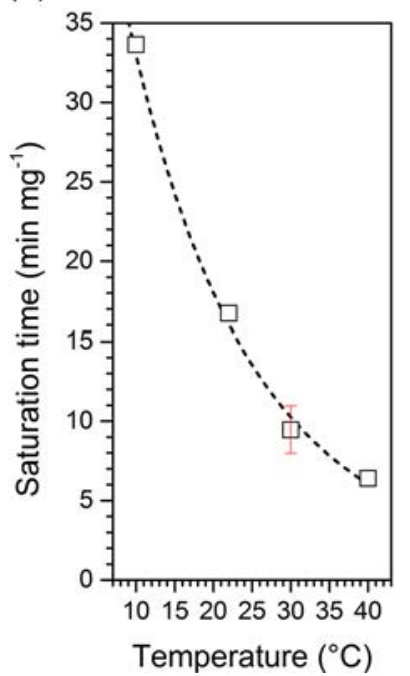

(b)

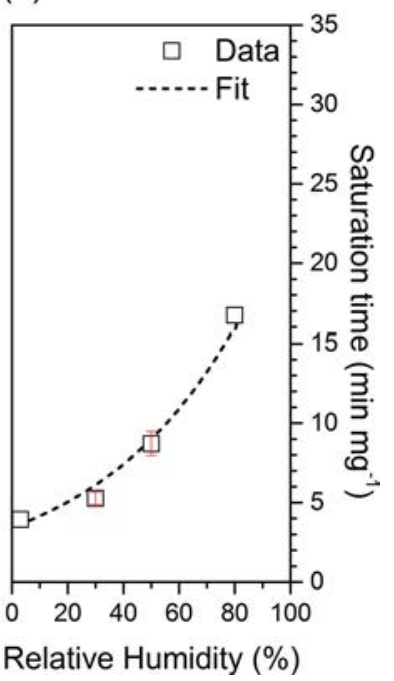

Fig. 9 Comparison between experiments and calculations: influence of a temperature at $80 \% \mathrm{RH}$ and b relative humidity at $22{ }^{\circ} \mathrm{C}$ on saturation time during sol-gel process 


\section{Discussion}

Despite the time to reach saturation used in this study being a powerful tool that can be used to characterize the process linked to drying phenomena, it does not correspond to the gelation time usually used. Indeed, the gelation time is defined as the time needed for the sol to be able to support an elastic stress.

This can occur before, during, or after the drying stage depending on several factors: ambient conditions; film thickness; substrate shape, as well as precursor reactivity as explained by Cairncross et al. [12, 17, 18]. Thanks to simulations, these authors showed that chemical reaction rates and internal and external mass transfer can modify the drying and gelation process, therefore leading to several microstructures. For example, when drying conditions are fast, chemical gelation period can be less than the time needed for drying solvents. This drying-before-gelation phenomenon corresponds to the drying of a liquid. Avoiding solvent encapsulations and limiting cross-linking lead to a denser coating with lower residual stresses. These authors also pointed out, from the evolution of the drying rates that three different stages occur during the drying process.

Deriving the experimental data of Fig. 2 allowed us to plot the experimental drying rates for the siloxane surface treatment used here (Fig. 10). Our results are consistent with the interpretations proposed by Cairncross et al. with the clear appearance of three periods when $\mathrm{RH} \geq 30 \%$.

In order to gain insight into these stages, from the chemical point of view, we plotted the normalized $-\mathrm{OH}$ and $\mathrm{Si}-$ $\mathrm{O}-\mathrm{Si}$ bond fraction in addition to the mass loss rates for $\mathrm{RH}$ $=30 \%$ (a) and 50\% (b) (see Fig. 11).

The first stage (I), corresponding to an initial period where the rate drops, was associated to a diffusional mass transfer resistance. During this stage, the solvent lost by evaporation was not replenished by solvent diffusion toward the surface of the coating - resulting in a reduced drying rate. In this study, the phenomenon was still accentuated by water uptake. This first falling rate period was accompanied by an increase in the normalized -OH bonds fraction, as seen in Fig. 11a, b. So the falling rate period was due, on the one hand, to alcohol diffusion through the coating thickness and, on the other hand, to water uptake.

The second stage - called steadying rate period (II) resembled the constant rate period discussed by Brinker and Scherer [5]. It results from drying a wetting liquid from a porous medium. In this stage, rates of diffusion of solvents toward the surface are counter balanced by their rates of evaporation, leading to a near constant drying rate. This is clearly visible in Fig. 11b. Between 2 and $6 \mathrm{~min} \mathrm{mg}^{-1}$, the mass loss rate was almost constant during drying as was the normalized $-\mathrm{OH}$ bonds fraction.

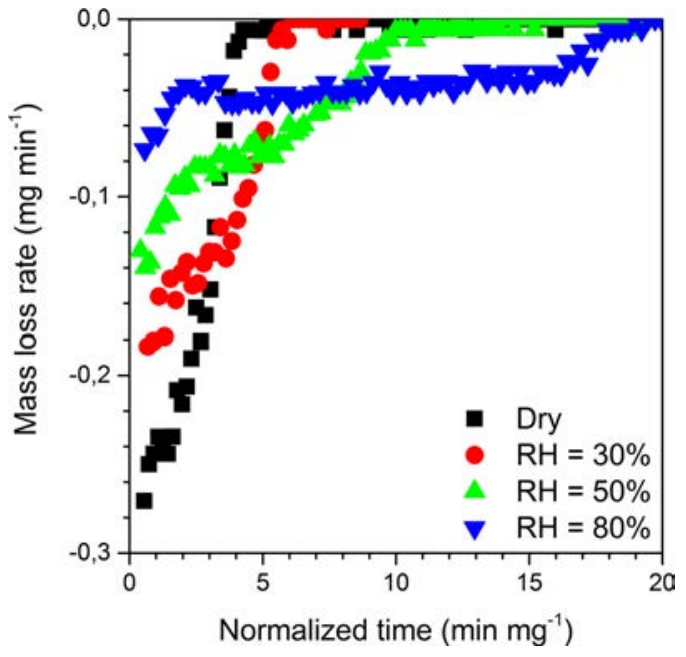

Fig. 10 Influence of relative humidity on mass loss rate during sol-gel process at $22{ }^{\circ} \mathrm{C}$, black squares: dry, red circles: $30 \% \mathrm{RH}$, green triangles: $50 \% \mathrm{RH}$, reverse blue triangles: $70 \% \mathrm{RH}$

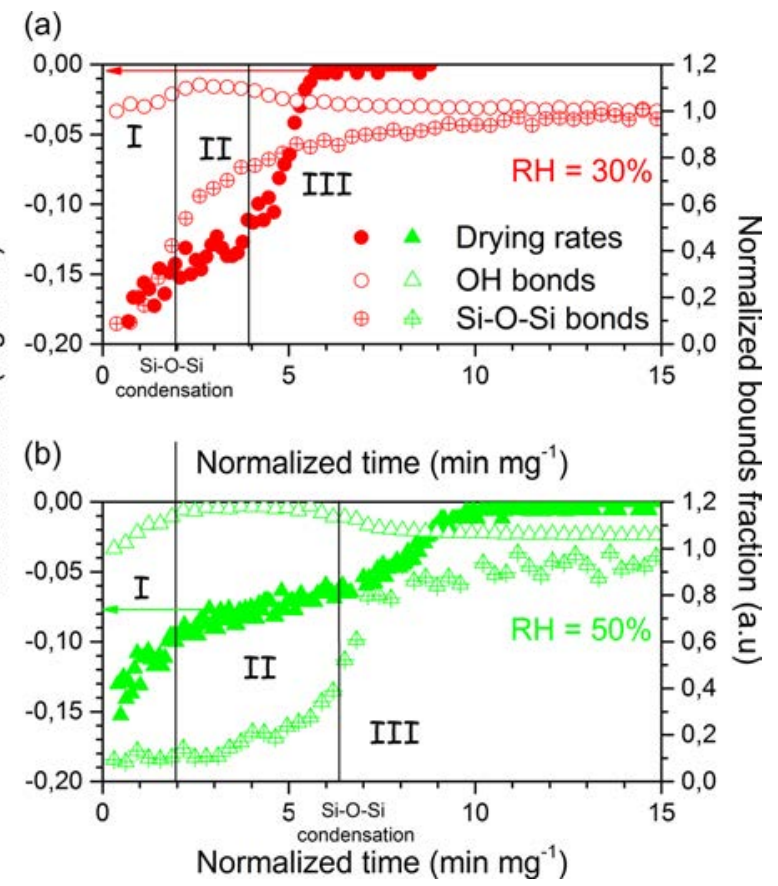

Fig. 11 Influence of relative humidity on mass loss rate and both $\mathrm{Si}-\mathrm{O}-$ $\mathrm{Si}$ and $-\mathrm{OH}$ normalized bonds fraction during sol-gel process at $22{ }^{\circ} \mathrm{C}$ : comparison between atmosphere with a relative humidity of $30 \%$ and b relative humidity of $50 \%$. Red circles: $30 \% \mathrm{RH}$, green triangles: $50 \% \mathrm{RH}$, filled shapes: instantaneous drying rate, empty shapes: normalized $-\mathrm{OH}$ bonds fraction, empty shapes with cross: normalized $\mathrm{Si}-\mathrm{O}-\mathrm{Si}$ bonds fraction

The third and final step occurs when the overall solvent content decreases and is called final falling rate period (III). At the end of the drying step, liquid diffusion was no longer sufficient to compensate for the mass loss through solvent evaporation. Liquid was then removed from the coating by diffusion of its vapor phase. This is illustrated by decreases 
in mass loss rate and normalized $-\mathrm{OH}$ bonds fraction after $6 \mathrm{~min} \mathrm{mg}^{-1}$ (see Fig. 11b).

In Figs. 10 and $11 \mathrm{a}, \mathrm{b}$, if the three stages were identified for each RH tested (except for the dry condition), noticeable differences were remarked. First, the value of the initial drying rate differed greatly with RH. This can be easily explained as this stage was assumed to be related to alcohol evaporation and water uptake. Moisture in the atmosphere was absorbed by the coating, limiting the diffusion of the alcohol to the surface and in turn reducing the evaporated solvent mass. Then, the value and the duration of the constant rate period (II) were greatly affected by RH. It was to be expected, since the flux of evaporation is linked to vapor pressure and RH. So, the value of the balance between rates of diffusion of solvents to the surface and evaporation is a function of RH. As evaporation decreased with $\mathrm{RH}$, the duration of the steadying state period increased. The flux of molecules leaving the coating per minute was lower. So the time needed to reach the final step where diffusion of the vapor phase occurred became longer.

At $30 \%$, the increase of the normalized $\mathrm{Si}-\mathrm{O}-\mathrm{Si}$ bonds fraction was very fast and reached an early maximum. This is probably due to a dry-before-gel phenomenon. The solvents were removed fast, accelerating the condensation reaction and increasing $\mathrm{Si}-\mathrm{O}-\mathrm{Si}$ formation rate. Then, solvents were all removed and the increase of $\mathrm{Si}-\mathrm{O}-\mathrm{Si}$ bonds was limited, as was the silica skeleton. The coating obtained at the end was probably partially condensed and largely anisotropic depending on the thickness, as proposed by Cairncross et al. for this kind of drying phenomenon [18].

At $50 \%$, the major increase of the normalized $\mathrm{Si}-\mathrm{O}-\mathrm{Si}$ bonds fraction occurred at the end of the steadying state period. This is probably due to a gel-before-dry phenomenon. Solvents were removed slowly enough for a chemical condensation reaction to occur during the steady state period. During this stage, normalized Si-O-Si bonds fraction increased slowly from 3 to $6 \mathrm{~min} \mathrm{mg}^{-1}$. Then, it probably accelerated due to skeleton formation, solvent expulsion and physical drying of the solvents remained. The coating obtained by this method is more condensed as stated from XPS analysis, as suggested by Cairncross et al. and probably more isotropic, as proposed by the same authors [18]. As already stated, these mechanisms also induced a modification of the chemical state of the gel formed - as discussed before (Fig. 4a, b).

\section{Conclusions}

In the present study, the influence of RH and temperature on the sol drying kinetics of a siloxane surface treatment was investigated thanks to a new methodology. In situ FTIR were performed during sol drying and the resulting films were analyzed by XPS. Gravimetric analyses were also performed with a DVS device. This new method to monitor sol drying was very effective to study the influence of both temperature and relative humidity.

When RH increased in the atmosphere, the time needed for drying raised too. It was related to water uptake and evaporation decrease. This led to a more condensed coating as confirmed by XPS analysis.

As it is described by an Arrhenius law when temperature increases, the time to dry decreases exponentially. Indeed, evaporation and chemical reactions are thermally activated with activation energy of $41.7 \mathrm{~kJ} \mathrm{~mol}^{-1}$. A double exponential law was proposed to calculate the time needed for drying the sol as a function of temperature and $\mathrm{RH}$.

The present experimental results are consistent with the previous simulation work [18]. We were therefore able to describe the drying phenomena of the siloxane surface treatment used. Differences were noticed between $30 \%$ and $50 \% \mathrm{RH}$ that are interpreted in terms of drying turned from a dry-before-gel to a gel-before-dry state. This was confirmed by XPS results with the formation of a more condensed coating at higher RH.

It is therefore obvious that both temperature and relative humidity should always be controlled during sol-gel process. From an industrial viewpoint, the present study allows us to propose that, drying should be performed in a moist atmosphere (RH higher than 50\%) in order to get a homogenous film. Otherwise, high evaporation process could lead to skinning phenomenon and/or partially uncondensed film.

Acknowledgements This work is part of the French Optisurf project, supervised by the IRT Jules Verne (Bouguenais, France). We would like to thank their industrial (General Electric, Socomore) and academic partners (Nantes University, CNRS). The authors also wish to thank Dr Mael Peron (GeM) and Pr Bernard Humbert (IMN) for their valuable help provided during this work, concerning DVS and FTIR measurements, respectively.

\section{Compliance with ethical standards}

Conflict of interest The authors declare that they have no conflict of interest.

Publisher's note: Springer Nature remains neutral with regard to jurisdictional claims in published maps and institutional affiliations.

\section{References}

1. Ebelmen M (1845) Chimie sur une production artificielle de silice diaphane. Comptes-Rendus Académie Sci 21:502-505

2. El Kass M, Brohan L, Gautier N et al. (2017) TiO2 anatase solutions for electron transporting layers in organic photovoltaic cells. Chemphyschem 18:2390-2396. https://doi.org/10.1002/cphc.201700306

3. Faustini M, Nicole L, Boissière C et al. (2010) Hydrophobic, antireflective, self-cleaning, and antifogging sol-gel coatings: 
an example of multifunctional nanostructured materials for photovoltaic cells. Chem Mater 22:4406-4413. https://doi.org/ $10.1021 / \mathrm{cm} 100937 \mathrm{e}$

4. Gharbi O, Thomas S, Smith C, Birbilis N (2018) Chromate replacement: what does the future hold? Npj Mater Degrad 2:12. https://doi.org/10.1038/s41529-018-0034-5

5. Brinker CJ, Scherer GW (1990) Sol-Gel Science: The physics and chemistry of sol-gel processing. Academic Press, London

6. Brinker CJ, Frye GC, Hurd AJ, Ashley CS (1991) Fundamentals of sol-gel dip coating. Thin Solid Films 201:97-108. https://doi. org/10.1016/0040-6090(91)90158-T

7. Grosso D, Boissière C, Faustini M (2015) Thin film deposition techniques. Sol-Gel Handb Synth Charact Appl 3:277-315

8. Sanchez C, Rozes L, Ribot F et al. (2010) "Chimie douce": a land of opportunities for the designed construction of functional inorganic and hybrid organic-inorganic nanomaterials. Comptes Rendus Chim 13:3-39. https://doi.org/10.1016/j.crci. 2009.06.001

9. Liu D-M, Troczynski T, Tseng WJ (2002) Aging effect on the phase evolution of water-based sol-gel hydroxyapatite. Biomaterials 23:1227-1236. https://doi.org/10.1016/S0142-9612(01)00242-3

10. El Hallani G, Fazouan N, Liba A, Khuili M (2016) The effect of sol aging time on structural and optical properties of sol gel $\mathrm{ZnO}$ doped Al. J Phys Conf Ser 758:012021. https://doi.org/10.1088/ 1742-6596/758/1/012021

11. Shahzad B, Qi Y (2011) A systematic study of solution aging time impact on surface morphology of sol-gel derived $\mathrm{ZnO}$ thin films. Adv Mater Res 216:271-277. https://doi.org/10.4028/www. scientific.net/AMR.216.271

12. Cairncross RA, Francis LF, Scriven LE (1992) Competing drying and reaction mechanisms in the formation of sol-to-gel films, fibers, and spheres. Dry Technol 10:893-923. https://doi.org/10. 1080/07373939208916487

13. Itaya $\mathrm{Y}$, Bessho N, Hasatani M (1999) Heat and mass transfer with polycondensation in resin film during drying. Dry Technol 17:2169-2181. https://doi.org/10.1080/07373939908917678

14. Liu L, Walcarius A (2017) Kinetics of the electrochemicallyassisted deposition of sol-gel films. Phys Chem Chem Phys 19:14972-14983. https://doi.org/10.1039/C7CP01775H

15. Perez EB, Carvalho MS (2007) Drying of thin films of polymer solutions coated over impermeable substrates. Heat Transf Eng 28:559-566. https://doi.org/10.1080/01457630701193989

16. Brinker CJ, Hurd AJ, Schunk PR et al. (1992) Review of sol-gel thin film formation. J Non-Cryst Solids 147-148:424-436. https:// doi.org/10.1016/S0022-3093(05)80653-2

17. Cairncross RA, Limbert A, Francis LF, Scriven LE (1994) Gravimetric Analysis of drying sol-gel derived coatings and comparison to theory. In: Attia YA (ed) Sol-gel processing and applications. Springer US, Boston, MA, p. 111-118

18. Cairncross RA, Francis LF, Scriven LE (1996) Predicting drying in coatings that react and gel: drying regime maps. AIChE J 42:55-67. https://doi.org/10.1002/aic.690420107

19. Li X, Rankin S (2010) Multiscale dynamic monte carlo/continuum model of drying and nonideal polycondensation in sol-gel silica films. AIChE J 56:2946-2956. https://doi.org/10.1002/aic.12202

20. Bera S, Rout TK, Udayabhanu G, Narayan R (2015) Comparative study of corrosion protection of sol-gel coatings with different organic functionality on Al-2024 substrate. Prog Org Coat 88:293-303. https://doi.org/10.1016/j.porgcoat.2015.07.006

21. Bera S, Rout TK, Udayabhanu G, Narayan R (2016) Water-based \& eco-friendly epoxy-silane hybrid coating for enhanced corrosion protection \& adhesion on galvanized steel. Prog Org Coat 101:24-44. https://doi.org/10.1016/j.porgcoat.2016.07.010

22. Le Blanc L, Campazzi E, and Savigne P (2007) Sol for sol-gel process coating of a surface and coating method by sol-gel process using same. Patent WO2007003828 (A2), 11 January 2007
23. Ramezanzadeh B, Raeisi E, Mahdavian M (2015) Studying various mixtures of 3-aminopropyltriethoxysilane (APS) and tetraethylorthosilicate (TEOS) silanes on the corrosion resistance of mild steel and adhesion properties of epoxy coating. Int $\mathrm{J}$ Adhes Adhes 63:166-176. https://doi.org/10.1016/j.ijadhadh.2015.09.007

24. Greenspan L (1977) Humidity fixed points of binary saturated aqueous solutions. J Res Natl Bur Stand Sect Phys Chem 81 A:89. https://doi.org/10.6028/jres.081A.011

25. Leopold HG, Johnston J (1927) The vapor pressure of the saturated aqueous solutions of certain salts. J Am Chem Soc 49:19741988. https://doi.org/10.1021/ja01407a019

26. Richardson GM, Malthus RS (2007) Salts for static control of humidity at relatively low levels. J Appl Chem 5:557-567. https:// doi.org/10.1002/jctb.5010051006

27. Winston PW, Bates DH (1960) Saturated solutions for the control of humidity in biological research. Ecology 41:232-237. https:// doi.org/10.2307/1931961

28. Gallas J-P, Goupil J-M, Vimont A et al. (2009) Quantification of water and silanol species on various silicas by coupling ir spectroscopy and in-situ thermogravimetry. Langmuir 25:5825-5834. https://doi.org/10.1021/la802688w

29. Innocenzi P, Kidchob T, Bertolo JM et al. (2006) Time-resolved infrared spectroscopy as an in situ tool to study the kinetics during self-assembly of mesostructured films. J Phys Chem B 110:10837-10841. https://doi.org/10.1021/jp060097x

30. Innocenzi P, Malfatti L, Kidchob T et al. (2007) Time-resolved simultaneous detection of structural and chemical changes during self-assembly of mesostructured films. J Phys Chem C 111:53455350. https://doi.org/10.1021/jp066566c

31. Antonucci JM, Dickens SH, Fowler BO et al. (2005) Chemistry of silanes: interfaces in dental polymers and composites. J Res Natl Inst Stand Technol 110:541-558. https://doi.org/10.6028/jres.110.081

32. Balgude D, Konge K, Sabnis A (2014) Synthesis and characterization of sol-gel derived cnsl based hybrid anti-corrosive coatings. J Sol-Gel Sci Technol 69:155-165. https://doi.org/10.1007/ s10971-013-3198-Z

33. Macan J, Ivanković H (2006) Influence of Hydrolysis Conditions on Curing and Properties of an Epoxy-Silane Based Hybrid Material. n: conference on materials, processes, friction and wear MATRIB 2006, Vela Luka, 22-24 June 2006, p. 99-104

34. Macan J, Ivanković H, Ivanković M, Mencer HJ (2003) Preparation of epoxy-based organic-inorganic hybrids by sol-gel process. International Conference MATRIB 2003, Materials, Tribology, Processing, Vela Luka, 26-28 June 2003, p. 129-134

35. Mansur H, Oréfice R, Pereira M et al. (2002) FTIR and UV-Vis study of chemically engineered biomaterial surfaces for protein immobilization. J Spectrosc 16:351-360. https://doi.org/10.1155/ 2002/183053

36. Nogami M (1985) Glass preparation of the $\mathrm{ZrO} 2-\mathrm{SiO} 2$ system by the sol-gel process from metal alkoxides. J Non-Cryst Solids 69:415-423. https://doi.org/10.1016/0022-3093(85)90043-2

37. Liu C, Bonaccurso E, Butt H-J (2008) Evaporation of sessile water/ethanol drops in a controlled environment. Phys Chem Chem Phys 10:7150. https://doi.org/10.1039/b808258h

38. Heideger WJ, Boudart M (1962) Interfacial resistance to evaporation. Chem Eng Sci 17:1-10. https://doi.org/10.1016/00092509(62)80001-3

39. Persad AH, Ward CA (2016) Expressions for the evaporation and condensation coefficients in the Hertz-Knudsen relation. Chem Rev 116:7727-7767. https://doi.org/10.1021/acs.chemrev. 5 b00511

40. Kita Y, Okauchi Y, Fukatani Y et al. (2016) Quantifying vapor transfer into evaporation ethanol drops in humid atmosphere. Phys Chem Chem Phys 18:21-46. https://doi.org/10.1039/C5CP05142H

41. Grosvenor AP, Kobe BA, McIntyre NS (2004) Studies of the oxidation of iron by water vapour using X-ray photoelectron 
spectroscopy and QUASES ${ }^{\mathrm{TM}}$. Surf Sci 572:217-227. https://doi. org/10.1016/j.susc.2004.08.035

42. Roberts MW, Wood PR (1977) The mechanism of the oxidation and passivation of iron by water vapour-an electron spectroscopic study. J Electron Spectrosc Relat Phenom 11:431-437. https://doi.org/10.1016/0368-2048(77)80018-2

43. Moulder JF, Stickle WF, Sobol RE, Bomben KD (1992) Handbook of X-Ray Photoelectron Spectroscopy: a Reference Book of Standard Spectra for Identification and Interpretation of XPS Data. Physical Electronics, Eden Prairie Minnesota

44. Brennan JF, Shapiro JS, Watton EC (1974) Evaporation of liquids: a kinetic approach. J Chem Educ 51:276. https://doi.org/ 10.1021/ed051p276

45. Kane SA, Iwuoha EI, Smyth MR (1998) Development of a solgel based amperometric biosensor for the determination of phenolics†. Anal (Lond) 123:2001-2006. https://doi.org/10. 1039/a803409e

46. Zientara M, Jakubczyk D, Kolwas K, Kolwas M (2008) Temperature dependence of evaporation coefficient of water in air and nitrogen under atmospheric pressure; study in water droplets. J Phys Chem A 21:5152-5158

47. Bansal NP (1990) Influence of several metal lons on the gelation activation energy of silicon tetraethoxide. J Am Ceram Soc 73:2647-2652. https://doi.org/10.1111/j.1151-2916. 1990.tb06741.x

48. Bechtold MF, Mahler W, Schunn RA (1980) Polymerization and polymers of silicic acid. J Polym Sci Polym Chem Ed 18:28232855. https://doi.org/10.1002/pol.1980.170180907 